\title{
Not so fast: the use of incomplete data to devalue the role of mammography screening
}

\author{
Daniel B. Kopans
}

Received: 12 January 2012/Accepted: 17 January 2012/Published online: 14 February 2012

(C) Springer Science+Business Media, LLC. 2012

\section{To the Editor,}

The recent article by Burton et al. [1] provides so many distractions that it would take pages and pages to unravel the prestidigitation. I have no doubt that the peer reviewers simply threw up their hands and supported its publication because it was so complex that they could not possibly untangle the reasoning.

The United States registry data show clear statistical fluctuations in the incidence and death rates from breast cancer, yet in Australia, with hundreds of millions fewer women, there seems to have been little fluctuation in the reported data The authors combined 2 years of data for each data point explaining that they wanted "to reduce the variability of rate estimates". Why are the years averaged for BreastScreen data different from the dates for the other data? How did this averaging influence the results? Averaging data has been used to, falsely, make the age of 50 appear as if it is a legitimate threshold for starting screening $[2,3]$ when, in fact, none of the parameters of screening change abruptly at the age of 50 or any other age [4]. How did their use of averaging influence their results? They should have provided the unaveraged data so that the reader could see the effects of averaging.

Why did the authors not provide data going back to at least 1980 ? In the mid 1980s, based on the mortality reduction in the Swedish 2 County randomized, controlled trial of screening mammography, screening began in the U.S. in sufficient numbers to influence National statistics, despite the fact that we had no organized screening program. I would be surprised if

D. B. Kopans ( $)$

Breast Imaging Division, Massachusetts General Hospital,

Harvard Medical School, Boston, MA, USA

e-mail: dkopans@partners.org
Australia was so far behind the U.S. There was likely much more screening in Australia before the start of BreastScreen than the authors report. In the U.S., as would be expected, there is a clear prevalence bump in the mid 1980s as screening began at a National level. Where is the prevalence bump in the Australian data following the start of BreastScreen? Was the lack of a bump due to the fact that many women were being screened prior to BreastScreen and the bump had already occurred?

The authors agree that therapy only works when cancers are found early stating that "The 1995 National survey reported that $85 \%$ of Australian women diagnosed with breast cancer had early disease" and that this was the reason that adjuvant therapies resulted in the decline in deaths. What changed in Australia that so many cancers were "early"? The authors should go back and determine how these "early cancers" were suddenly so common. I suspect they will find that mammography screening was the main reason and that this allowed therapy to save lives.

Conflict of interest None.

\section{References}

1. Burton RC, Bell RJ, Thiagarajah G, Stevenson C (2011) Adjuvant therapy, not mammographic screening, accounts for most of the observed breast cancer specific mortality reductions in Australian women since the national screening program began in 1991. Breast Cancer Res Treat

2. Kopans DB (2005) Bias in the Medical Journals: a commentary. AJR Am J Roentgenol 185:176-182

3. Kopans DB (2005) Informed decision making: age of 50 is arbitrary and has no demonstrated influence on breast cancer screening in women. AJR Am J Roentgenol 185:177-182

4. Kopans DB, Moore RH, McCarthy KA, Hall DA, Hulka C, Whitman GJ, Slanetz PJ, Halpern EF (1998) Biasing the interpretation of mammography screening data by age grouping: nothing changes abruptly at age 50. Breast J 4:139-145 